\title{
Policy and Financing in Family Medicine and the Medical Home
}

This month we have several articles about policy and financing related to family medicine and the medical home. Setting the stage, Tsai et $\mathrm{al}^{1}$ present the primary care outcomes of the Taiwanese universal health care system, an interesting juxtaposition to health care reform discussions in the United States. Specifically, the authors discuss the negative impact of the unrestricted access to specialists as a usual source of care on the quality of primary care services. Stenger and $\mathrm{DeVoe}^{2}$ follow this and review 59 recent legislative bills ( 25 of which were enacted) intended to encourage the medical home in the United States; not surprisingly, they note that the definition and mechanisms differ substantially state to state. This sets the stage for a natural experiment to suggest which interventions create better outcomes and can further inform additional health policy changes. Ohman-Strickland et $\mathrm{al}^{3}$ provide indications of the chronic care model features that are associated with improved diabetes care, suggesting those that should be specifically encouraged.

Meantime, Saultz and colleagues ${ }^{4}$ decided to do something about the lack of health care for the uninsured, and did so directly at 2 family medicine offices. Their plan is fascinating, successful, and could potentially be used in other locales. Perhaps the most interesting aspect is that most of the uninsured patients who signed up and paid on a simplified sliding scale for the plan had incomes more than $400 \%$ of poverty level. These patients apparently most wanted guaranteed access to care and had trouble finding it when they were labeled "uninsured." This is a lesson for our national health care policy.

In a fascinating discussion, Mold et $\mathrm{al}^{5}$ remind us of diminishing returns in medicine; more money does not mean better care, and the trick can be to decide when to stop pursuing each less-rewarding step. For a disease entity with several well-researched effective treatments, the

Conflict of interest: The authors are editors of the $7 A B F M$. first one or 2 provide most of the benefit that can be gained (look at the table in this article to see how this works!). This clearly epitomizes one of the major problems in the US health care system. Separately, Krist et $\mathrm{al}^{6}$ also provide a methodology for family physicians to estimate their costs for implementing aspects of the medical home, which can help determine which portions of the medical home should take priority-the law of diminishing returns probably also applies to bow we practice.

Intimate partner violence is often associated with increased medical care utilization, as is noted in the increased charges and utilization found by Porcerelli et al. ${ }^{7}$ These authors note that the increased utilization only occurs in association with psychiatric symptoms, ie, those without an excess of mental health complaints do not have increased utilization. However, as noted by Chen et $\mathrm{al}^{8}{ }^{8}$ intimate partner violence may have effects that differ by type of utilization; they found that intimate partner abuse (physical or sexual) reported by women older than 40 was associated with lower rates of cancer screening. It would be interesting to extend this information to consider whether or not this was related to psychiatric symptoms rather than any reported abuse, as found in the article by Porcerelli et al. ${ }^{7}$

We have 2 articles related to childhood obesity, an epidemic we hope to control to prevent later problems among adults. Duggins et $\mathrm{al}^{9}$ look at comfort with screening and counseling in the office. Family physicians often screen with body mass index and wish they had more time and resources to support treatment of childhood obesity. Unfortunately, in a real-world trial, the seemingly simple intervention of providing YMCA memberships in addition to nutrition classes did not improve childhood obesity; however, there were widely varying results among individuals, and it was not a large trial. We hope others will consider repeating a trial using health club membership.

Another childhood problem with significant implications for adult health is childhood can- 
cer. ${ }^{10}$ Every time I (MAB) read about this, I think about several of my patients. The effects from childhood cancer care can be very obvious or quite subtle. One patient who had radiation to her chest as a child has marked kyphoscoliosis, fibrosis of her lungs, and uncontrollable reflux (including reflux into her lungs). She gets short of breath easily and cannot recline below $\sim 60$ degrees without feeling like she is drowningradiation damage to the esophagus is at least partially to blame. Every day her life is significantly affected by the life-saving treatment she received as a child. A middle-aged patient who received radiation to his chest during childhood now has radiation damage to his coronary arteries, making his recent coronary artery bypass more difficult and possibly less effective in the long term. He also has hypothyroidism and has developed a second malignancy. In the study by Schwartz, ${ }^{10}$ several symptom clusters were common among childhood cancer survivors, and they reported twice as many problems than did the control group. As family physicians, understanding and recognizing the long-term effects of cancer care can help us better treat our patients.

Kanodia et $\mathrm{al}^{11}$ find that most patients across the nation who used complementary and alternative medicine for back pain found it useful, with yoga/ tai chi/qui gong and acupuncture receiving the best ratings. We agree these techniques can be good for back pain! The patients were most likely to perceive benefit when they did not think conventional medicine would help.

Edwards et $\mathrm{al}^{12}$ presents an overview of common and/or significant diseases of the oral cavity that the family physician is likely to encounter, with an emphasis on pathogenesis, recognition, management and complications. Family physicians see a lot of dental problems, and Edwards provides pictures, reviews common diagnoses, and suggests what family physicians can do as a first-line provider. Many patients have no dental provider, and they often come to family physician offices with pain. Edwards helps us think through the potential causes and next steps and reminds us that primary care has an important role in prevention and early detection of oral health problems.

We have a couple of brief reports with good cases and reminders. Elephantiasis nostras verru$\operatorname{cosa}^{13}$ is more common than we note it as an entity in the medical record. There are good pictures, differential diagnosis, and suggestions for management. Senthilvel et $\mathrm{al}^{14}$ reviews a case of adultonset Still disease.

Our fifth practice-based research network theme issue will be released in July 2010.

Marjorie A. Bowman, MD, MPA Anne Victoria Neale, PhD, MPH

\section{References}

1. Tsai J, Shi L, Yu W-L, Hung L-M, Lebrun LA. Physician specialty and the quality of medical care experiences in the context of the Taiwan National Health Insurance system. J Am Board Fam Med 2010;23:402-12.

2. Stenger RJ, DeVoe JE. Policy challenges in building the medical home: do we have a shared blueprint? J Am Board Fam Med 2010;23:384-92.

3. Ohman-Strickland PA, Hudson SV, Piasecki A, et al. Features of the chronic care model (CCM) associated with behavioral counseling and diabetes care in community primary care. J Am Board Fam Med 2010;23:295-305.

4. Saultz JW, Brown D, Stenberg S, et al. Access Assured: a pilot program to finance primary care for uninsured patients using a monthly enrollment fee. J Am Board Fam Med 2010;23:393-401.

5. Mold JW, Hamm RM, McCarthy LH. The law of diminishing returns in clinical medicine: how much risk reduction is enough? J Am Board Fam Med 2010;23:371-5.

6. Krist AH, Cifuentes M, Dodoo MS, Green LA. Measuring primary care expenses. J Am Board Fam Med 2010;23:376-83.

7. Porcerelli JH, Cogan R, Markova T, Murdoch W, Porcerelli MA. Abuse, outpatient charges and utilization, and psychiatric symptoms among urban women on Medicaid. J Am Board Fam Med 2010; 23:363-70.

8. Gandhi S, Rovi S, Vega M, Johnson MS, Ferrante J, Chen P-H. Intimate partner violence and cancer screening among urban minority women. J Am Board Fam Med 2010;23:343-53.

9. Duggins M, Cherven P, Carrithers J, Messamore J, Harvey A. Impact of family YMCA membership on childhood obesity: a randomized controlled effectiveness trial. J Am Board Fam Med 2010;23: $323-33$.

10. Schwartz LA, Mao JJ, DeRosa BW, et al. Selfreported health problems of young adults in clinical settings: survivors of childhood cancer and healthy controls. J Am Board Fam Med 2010;23: 306-14.

11. Kanodia AK, Legedza ATR, Davis RB, Eisenberg DM, Phillips RS. Perceived benefit of complementary and 
alternative medicine (CAM) for back pain: a national survey. J Am Board Fam Med 2010;23:354-62.

12. Edwards PC, Kanjirath P. Recognition and management of common acute conditions of the oral cavity resulting from tooth decay, periodontal disease, and trauma: an update for the family physician. J Am Board Fam Med 2010;23:285-94.
13. Baird D, Bode D, Akers T, DeYoung Z. Elephantiasis nostras verrucosa (ENV): a complication of congestive heart failure and obesity. J Am Board Fam Med 2010;23:413-7.

14. Senthilvel E, Papadaki A, McNamara M, Adebambo I. Adult-onset Still disease (AOSD). J Am Board Fam Med 2010;23:418-22. 